\title{
Corona Virus Disease (COVID-19) Effects on Language Use: An Analysis of Neologisms
}

\author{
Jefwa Mweri \\ Department of Kiswahili, Kenya Sign Language Research project (KSLRP), University of Nairobi, Kenya
}

Received August 24, 2020; Revised January 18, 2021; Accepted January 28, 2021

\section{Cite This Paper in the following Citation Styles}

(a): [1] Jefwa Mweri , "Corona Virus Disease (COVID-19) Effects on Language Use: An Analysis of Neologisms," Linguistics and Literature Studies, Vol. 9, No. 1, pp. 36 - 47, 2021. DOI: 10.13189/lls.2021.090105.

(b): Jefwa Mweri (2021). Corona Virus Disease (COVID-19) Effects on Language Use: An Analysis of Neologisms. Linguistics and Literature Studies, 9(1), 36 - 47. DOI: 10.13189/lls.2021.090105.

Copyright $\bigcirc 2021$ by authors, all rights reserved. Authors agree that this article remains permanently open access under the terms of the Creative Commons Attribution License 4.0 International License

\begin{abstract}
The corona virus disease has impacted virtually everybody in the world today by introducing various changes leading to what has come to be known as the new normal. This paper gives COVID-19 a new perspective from the medical one that is always examined. It analyses how the English language has been able to adapt to the changes that COVID -19 has occasioned. Because it is dynamic, language changes to accommodate new happenings in society for example introducing or coining completely new words into their vocabulary through word formation processes such as blending and acronymy or through old words acquiring new meaning (semantic shift) or old words gaining currency due to an emerging and trending situation. These word formation processes are examples of neologisms. This paper therefore is an analysis of language of social crisis and it examines neologisms in the wake of COVID-19 by shading some light on how some of the words and phrases being used in what we will call corona vocabulary came into existence or how they are used in the context of a catastrophic event that COVID-19 is. Through a descriptive qualitative method of analysis, we obtain and analyze information on what we consider a trending issue of global concern - COVID-19. Data were collected from different sources about language use in the realities of the pandemic. The words and phrases were obtained from social media, daily newspapers and other writings that revolved around the issue of COVID-19. Similarly, we draw from various theoretical approaches to neologisms discussed by Rets and others. We also account for the changes in language use that have been occasioned by COVID-19 by using MAK Halliday functional theory that posits that language changes are occasioned by the needs of its users.
\end{abstract}

Keywords COVID-19, Language, Change, Neologism

\section{Introduction}

Language as a dynamic system can introduce new ways of referring to things that have always been there and those which come into existence later on. Languages can be adapted to reflect changes taking place in the life and culture of users, and the majority of such changes happen in their vocabulary, because as compared to vocabularies that can change very quickly both in its lexicon and in word meanings, grammatical and phonological structures of language are relatively stable and take time to change. [1] Since its advent, COVID- 19 has brought a totally new approach to people's life over the world and language has not been spared. In this paper, we explore and explain some of the new ways of referring to things manifested in language during the pandemic. We do this through an analysis of neologisms which include new words that have been added to the English vocabulary through such processes as blending and acronymy; completely new coinages and old words that have acquired new meaning (semantic shift) or have gained currency due to the pandemic.

The noun neologism is a coinage from the Greek root neo-, which means 'new', and logos, which means 'word.' What stands out in the many definitions of neologism is the fact that it involves coining or inventing new words or expressions and how they are used or how old words are used in new senses. Thus, whenever a new word or 
expression is coined and used or when an existing word or expression assumes a new meaning in language, a neologism is formed. Therefore, any newly formed word or phrase or any word which has gained a new meaning is a neologism [2].

The process of neologism which causes the variation in the features of language produces language change. This change happens over time to all languages. According to Britannica.com, [3] Languages change in their pronunciation, lexicon, and sentences and in meaning. These changes happen gradually and are noticeable across several generations. However, it is the lexicon that is subject to changes that are expeditious and discernible.

The COVID-19 pandemic has been a catalyst of culture change and some of these changes manifest themselves in language use. Languages have been known to acquire new words or new expressions in their workings. Neologism are mostly products of invention and innovation; however, language change can occur from other sources. For instance, [4] language can change through language learning; as it is being transmitted from generation to generation, language is transformed. This happens since each user of language re-invents the grammar and lexicon of their language based on the code received from the speech community. Thus, individual language use causes systematic language change. In addition, though some of these changes may seem haphazard they may spread and become permanent especially in small populations. [4]

According to Noviarianti [5], language contact can lead to change via migration, conquest and trade, all of which serve to bring speakers of different languages into contact. Due to these contact situations, languages borrow aspects of other languages such as words, sounds, constructions and so on. On the other hand, social groups try to differentiate themselves by adopting distinctive ways of doing things reflected in their norms of dress, adornment, gesture etc. Through language, groups can also differentiate themselves. For example, languages are distinct when it comes to vocabulary for example in their usage of slang or jargon, or through how they pronounce words or through morphological processes and syntactic constructions etc. These differences occasion change. Languages also change through its usage. For example, the use of rapid or casual speech in natural conversation produces processes that can lead to change such as assimilation, dissimilation, syncope and apocope. Similarly, particular cases of repetition may be conventionalized with time and end up producing slower or more careful speech. Conventionalization of processes like metaphor and metonymy can lead to word meaning changes. [6]

From the explanations above, it is clear that languages can change their vocabulary very easily as compared to their syntactic and phonologic structures which are relatively unchangeable over time. This means that in the course of using their language, users have the options of adopting new words, coming up with new meanings for existing words, or not using some words at all or not using them in particular meanings. Thus these language changes serve to accommodate new happenings in society and occur through word formation processes such as blending and acronymy or through old words acquiring new meaning (semantic shift) or sometimes old words can gain currency due to an emerging and trending situation like COVID-19. According to iugaza.edu.ps > files [7], the constant evolution of a new lexicon and the way that old words may develop new uses is an encouraging sign of the liveliness and ingeniousness. How the needs of the users of a language shape and how it is used also reflect its dynamism. This paper, therefore, discuses some innovations in language lexis and meaning by examining neologisms in the wake of the emerging and now trending COVID-19 pandemic.

\section{Methodology}

This research uses a descriptive qualitative method of analysis. The descriptive data in the form of written words is observed. The process enables us to relate ideas, perceptions, opinions that cannot be measured by numbers but are represented in words. [8] This qualitative descriptive study aims at obtaining and analyzing information on a trending issue of global concern COVID-19.

\section{Data sources}

The study collected data from different sources about language use in the realities of the pandemic. The study analyses a select number of words and phrases that have been in use during the pandemic. The words and phrase were obtained from social media, daily newspapers and other writings that revolved around the issue of COVID-19. The study analyses neologisms such as portmanteaus or blending, the process of acronymy and how it has contributed to the post COVID-19 vocabulary, coinages, and words whose meaning has changed (semantic shift) in the wake of COVID- 19 and those which have gained prominence or currency during the same period.

\section{Theoretical underpinnings}

There are several theoretical approaches to the issue of neologism. For example, the historical approach considers time as the basic criteria and thus defines neologism as any word whose origin is currently in the memory of the generation of its users. This view is supported by Šipka [9] who defines a neologism as a word which has only entered the lexicon recently. Rets [10] identifies what he calls basic theories of neologism which describe neologisms from different perspectives thus the understanding of neologism will differ, depending on the theory and approach adopted. The theories include: the stylistic 
theory which designate neologisms as words which are stylistically marked by the newness in their usage in the language. The structural theory on the other hand defines neologisms as words with a completely new configuration and shape or has unique audio pattern. However, the Etymological theory interprets that neologisms consist of words already in existence in a language but have developed new meaning in recent years. The lexicography theory characterize neologisms as words which have not been included in current dictionaries.

The above theoretical approaches have relevance to this study. They were used to account for some of the changes discussed. For instance, some of the neologisms discussed are in terms of style marked by their newness of their usage since they belong to the medical jargon, for example, the terms epidemic, pandemic, incubation period, ventilators, respirators etc. Structurally, we also discuss words with completely new configuration and shape words or unique sound pattern. These are the new coinages such as Rona, covidiots or moronaviruses etc. Etymologically, we also discuss words which have undergone meaning shift for instance the word plateau or new normal etc. In a way we shall be explaining how in their use within the COVID-19 discourse some words and phrase are neologisms. Our analysis is intralinguistic and analyses neologisms within the English language.

Rets [11] asserts that language development has a logical nature characterized by two prevailing forces. The- kinematic or active part which serves as a motivation for language change. The static or fixed part which aims at maintaining the stability or firmness of the language system so that it fulfils its functions. For this reason, language endeavors to be consistent and stable so as to satisfy the communication needs of its users. However, it also strives to reflect the reality of its usage in different areas of human undertaking and thus it undergoes constant change. This change can be external, for example, through scientific discoveries or through intercultural interaction or intralinguistic factors that motivated their formation. Shamne \& Rets [12] identify intralinguistic factors such as those motivated by language succinctness or how articulate the linguistic means is; How systematized the vocabulary is; how unified linguistic signs is; transformation and the switch in stylistic usage of the words. All these intralinguistic factors generate neologisms. This paper examines theses intralinguistic factors and their contribution to COVID-19 neologisms.

Since neologism occasions language change, this study adopts the functional theory proposed by M.A.K. Halliday [13]. This theory describes language change as occurring to the needs of its users. Just like this theory, this paper focusses only on lexical change. Thus, we will use the functional theory to account for some of these changes. The fact that language changes occurs to the needs of its users can be exemplified in many ways. For instance, through the adaptation of technological advancement, some words have been discarded in language because some technology has gone out of use while the new ones come into use. Words like cassette, video, floppy disc are slowly disappearing and words associated with new technology such as USB, flash disk, etc. are taking their place. New words, therefore, can be used to label new innovations and discoveries since language changes to suit the needs of its users. Below we discuss some of the neologisms that have come into use due COVID-19.

\section{Portmanteaus or blending}

Words in a language may be created through the process of blending or portmanteaus where two words are brought together to create a new word which combines their meanings. However, in blending, unlike compounding, only parts of the words are used usually after undergoing a clipping process. In the creation of these kinds of neologisms, the beginning of one word can be combined with the end of another word for example smoke + fog $=$ smog, breakfast + lunch $=$ brunch, motor + hotel $=$ Motel etc. Certain words in the COVID-19 vocabulary have been created using this strategy. For instance, the term COVID -19 itself is a blending derived from Corona Virus Disease -2019, giving us a completely new term or word. The term COVID-19 combines the first two letters of three different words and then adds a numeral and uses a hyphen as a linking element. Other examples of blended terms after COVID include: infodemic is a portmanteaus of "information" and "epidemic." The term infodemic refers to the rapid and extensive spread of correct and incorrect information about something, such as a disease to the extent that its solution is made more difficult. It also involves the swift escalation of misinformation, devoid of facts, full of rumors, leading to a situations where it becomes difficult to learn essential information about an issue such as COVID-19. Though the term Infodemic is not new, which was coined in 2003, it has been seen renewed usage during the COVID-19 period. According to the etymological theory, infodemic is an example of a word already exist in a language but has developed a new meaning recently; in this case, it is motivated by the pandemic. In this period of COVID-19, there has been an overload of information about the pandemic. Some are true and some are false. Making it impossible to distinguish between facts and fiction about the pandemic. Information overload has several effects on people. It can slow down people's productivity and their ability to make timely decisions. Simply put, information overload shuts our brains down! [14]

Another example of a blended word post corona is telemedicine a blend from "telephone" and "medicine." It involves the diagnosis and treatment of patients by means of telecommunications technology. Telemedicine can also 
refer to the situation where patients are cared for virtually especially in circumstances where it is not possible for the provider and patient to be physically present with each other for example in the pandemic situation. Through modern technology doctors are able to consult patients by using technological tools.[15] With COVID-19, people are encouraged to stay at home and reduce social contact to minimize the risk of infection. Because of this, many people avoid going to the hospitals for fear of contracting COVID-19. For example, the Kenyan government expressed concern with reports that many Kenyans had ceased visiting hospitals for fear of contracting Covid-19. The ministry of health however encouraged Kenyans who require medical services to visit hospitals since measures were in place to protect both the doctors and patients from getting infected. Similarly, the number of pregnant women seeking prenatal services in hospitals also went gone down" [16]. From the above, it is clear that if telemedicine was entrenched and used well, it could circumvent this challenge. The term telemedicine therefore is a neology marked stylistically by the newness of its usage in the language: it falls under the metalanguage or medical jargon that normally functions to convey hidden meanings accepted and understood in a specific field in this case the field of medicine. However, the term has entered the COVID-19 discourse and is no longer considered a jargon.

Other examples of blending are: Coronapocalypse blended from "corona", "apocalypse" and "coronageddon", which is blend of "corona" and "armageddon." These blends are considered as a form of wordplay. For "coronapocalypse", the word play centers around "apocalypse" which is added to the word corona. For the term "coronageddon," the word play centers around "armageddon" which is added to the term "corona." These terms are used convey some form of hilarity, and modesty enabling people manage COVID-19 and quarantines that come with it. [17 The term covidiot is a blend of "COVID-19" and "idiot", it is used as a slang insult against anyone who ignores the WHO health and safety guidelines about the novel coronavirus. A covidiot is one who exhibits the following characteristics: not washing their hands regularly, one who mingles in large groups of people, someone who does not observe social distancing that is six-feet distance between people, or those who hoards necessary items like toilet paper and hand sanitizer or those who unnecessarily go against the grain while the health protocols are urging everybody to do the opposite.

Another term that is used to insult people who are not following the health directives is moronavirus. This an example of word play; and in its coinage, the wordplay centers on the word moron, to which the term virus is added. The two terms (covidiot and moronavirus) can also be viewed as a form of quarantine shaming. Quarantine shaming is the use of slang for purposes of publicly rebuking anyone that is reluctant to follow the WHO outlined health and safety guidelines. It is also used to call out those who do not abide by the recommended health protocols through flagrant transgressions. [18]

Due to COVID-19, staycations are also becoming popular. A staycation is a portmanteau which brings together "stay" and "vacation," it is also known as holistay a blend of "holiday" and "stay." This is a form of domestic tourism. COVID-19 has given the world more prominence. With more time staying at home or sheltering in place orders, many people all over the world have opted for holidays at home or having staycations. People participate in leisure activities within driving distance of their home and eventually go back. [19]

The use of the blended words discussed above can be accounted for within Halliday's theory that stipulates that languages change to accommodate the needs of its users. Languages device strategies like blending that can be used to meet these needs. According to Halliday, language operates differently in different social situations, it is therefore bound to vary to suit the purpose of the users or a particular social situation. In this case, language uses blending as a strategy to create words that are used during the COVID-19 pandemic. Each blended word therefore unfolds in some context of use which also gives it its function. Thus, the blended words like COVID-19, Infodemic, coronapocalypse and coronageddon above serve the function of keeping people safe and informed about the deadly virus. Some are also a form of word play which serve to bring humour that can help people cope with the stress occasioned by COVID-19. Slang insults such as covidiot and moronavirus are used to shame those who do not follow heath protocols in the fight against COVID-19.

\section{Acronymy}

An acronym is a word that formed from the first letters of different words and pronounced as a word on its own right. Examples of acronyms used post COVID-19 are BC which stand for Before Corona and AC for after Corona. The two acronyms are used to denote things that were there pre-corona (old normal) and those that are post corona (new normal). Another example of an acronym associated with COVID-19 is the term WFH (Working From Home) which indicates the fact that employees have been forced to work at their homes rather than work in their offices. This has been made easy through the use technological tools such video conferencing and other collaborative technologies which enables people who work together liaise and stay in touch, regardless of their geographical location. [20]

The acronym PPE (Personal Protection Equipment) refers to appliances used to reduce the vulnerability caused by dangers that may cause serious injuries and illnesses at the workplace. PPEs are not limited to the 
medical field. However, the acronym PPE has been associated with medical workers who are in the forefront of fighting COVID-19. PPEs are part of the infection prevention and control measures against disease. Since COVID-19 is a highly infectious airborne disease and it can be contracted via infected surfaces, medical workers require PPEs that may include those that protect the face e.g., goggles, mask or face shields, gloves for the palms, gown or coverall, head cover and rubber boots to cover the whole body etc., all of which help protect the health workers from the virus.

The use of acronyms can be seen in light of the need to increase the amount of information passed in a short space of time thus occasioning the shortening of the lexis. Thus, acronyms serve the function of shortening complex words and phrases and make them more concise and easily understood. The conciseness and catchiness exhibited by acronyms whether written or through help in speeding up and facilitating communication. Hijazi [21] gives three functions of use of acronyms. They are time-saving due to their succinctness; they optimize space in printing, since individual letters stand for full phrases and/or compounds; and they facilitate the understanding of the original phrases or compounds being used. Therefore, all languages have a preference for using acronyms. Acronyms such as BC, AC, WFH and PPE discussed above are examples of initialisms i.e. acronyms that use all capital letters or uppercase letters and which are pronounced individually as words. They drop the full stops that normally accompany such abbreviations.

\section{Coinages}

As a neologism, coinage is a process of word formation in which a new word or expression is created either intentionally or fortuitously and often from seemingly nothing. A coinage can also be viewed as the invention of totally new terms. Some examples from everyday use of language, according to Yule [22], include aspirin, nylon, vaseline, Kleenex, google etc. These and many others have become widely used expressions today though they were created from seemingly nothing. Though coinages are a rare method of creating new words, some COVID-19 vocabulary is created using this strategy. Examples include the word Rona which is clipped from the word corona. It is also a clipping of coronavirus. Rona is made of double clipping, and is a playful or sarcastic way of referring to COVID-19, especially in respect to the amusing challenges brought about by social distancing during the pandemic. Rona therefore, is a term that brings humour and thus some form of relief. The term Rona is an example of a coinage that is compelled by the linguistic economy just like the use of abbreviations, many of which are neologisms.

Virtual happy hour is a term that was coined to mitigate the effects of corona fatigue. Because of COVID-19, people were forced to WFH. To relax after a long boring day they held virtual happy hours through the use of technological tools such as Zoom, FaceTime, Google Hangouts, and other video conferencing or chat applications. In an attempt to fight COVID-19 and flatten the curve, the focal point became social distancing and self-isolating; in the process many restaurants and bars were closed, and at the same time social gatherings with friends and family put on the back burner. In times as scary as these, many people desire to bond more than ever, since they are going through really rough time having to forego many social activities such dinner plans or going out with friends and colleagues. To mitigate against this, many offices used conferencing platforms to hold virtual happy hours in which a semblance of normalcy was restored by enabling people to have similar casual and social conversations while physically isolating. [23]

Due to lockdowns and the closing of services, many people were unable to keep appointments with their barbers thus growing bushy beards. These can be referred to as COVID beards. Many others were forced to trim or shave their beards off so as to be able to wear masks properly. However, the real COVID beard in COVID-19 discourse is one where a person wearing a mask pulls it down to their chin. This does not assist in the fight against being infected or infecting others. These are acts of covidiots or moronaviruses. The terms covidiots and moronaviruses themselves are examples of coinages though they have been discussed under blending.

The term Corona fatigue is used to refer to the very slow-moving game of viral roulette that is wearing down people everywhere. After being quarantined, lock downs, sheltering in place, people feel a little more drained. Quarantine life ends up being dull, taxing and sometimes an exacting experience. According to Ehrman, corona or quarantine fatigue can be associated with the following effects: irritability, feeling under pressure, apprehension, over eating, starving oneself, insomnia and lacking motivation. All of this is overwhelming and the fatigue is compounded by the unreliability and the unpredictability and the fear of the unknowns in all of this. To give a better perspective, she uses the analogy of an ocean and says: "It's like we're in the middle of the ocean. The ocean is COVID-19 and we're not seeing land anywhere. It's that feeling of helplessness. Like there's nothing you can do — or you can do everything right and still get sick.” [24]

Zoom-bombing is another coinage used in the COVID -19 vocabulary. The pandemic has seen a revolution in the usage of technology. There has been an explosion in the use of Zoom, Google meet, WhatsApp, Instagram, Facebook live streaming, all of which have been able to fill the void left by social distancing. People can communicate with their loved ones at ease. Work places can conduct meeting at a social distance as employees work from home. Even very traditional institutions that have always been reluctant in embracing technology like 
religious organizations have now been roped in. Since the closure of places of worship, most people do it via streaming live services like Facebook etc. However, the use of the internet for meetings, religious services etc. can fall victim to zoom-bombing. A new coinage in its own right. This happens when unknown people disrupt a virtual meeting by zoom-bombing with various obscene, violent, or offensive images or words.

\section{Old words new meaning (Semantic shift) or new prominence}

Writing about new vocabulary learnt during the pandemic, Kairu [25] discusses what he considered as new vocabulary learnt during the pandemic. However, what he discusses are not really new words but rather words that have undergone semantic shift or have gained prominence post COVID-19. Since common parlance is in contact interaction with different sociolects, sublanguages or metalanguage it creates an appropriate condition that allows some lexical items to change their register and enter public conversation. Rets [26]. Similarly, semantic shift is not a change in meaning per se, but can add meaning to the semantic system or indicate the loss of a meaning from the semantic system while the form is maintained. Whenever the cultural scripts shift in a society, vocabulary or lexicon of a language will also shift. Similarly, meanings of words themselves may change, to reflect and/or promote cultural change. COVID-19 is certainly an agent of culture change and some of these changes are reflected in the way that certain words have shifted their meaning to suit the pandemic situation. Examples of such words or expressions are discussed below:

\section{Symptomatic vs. Asymptomatic}

The term symptomatic is used to refer to the act of manifesting symptoms or refer to a specific symptom. A Symptom is a sign of disease or injury. Many medical conditions and maladies exhibit symptoms for example a cough can be a symptom of one having an infection of the upper respiratory organs. If someone has symptoms associated with a certain disease or condition, they are considered symptomatic. On the other hand, if one has a disease without detectable symptoms, they are considered asymptomatic. Both of these terms have been used in the metalanguage of medical jargon but they apparently gained more prominence during this period of COVID -19 . The term asymptomatic is also a product of a word formation process called affixation where a prefix or suffix is added to a base to create a new word. In the case of the term asymptomatic, a prefix "a" - is added to the adjective symptomatic which literary means showing symptoms. "A-" is a negative prefix in English that is added to nouns or adjectives to mean "lacking in." Thus someone who is asymptomatic is lacking in symptoms but could be infected and could possibly spread the virus. Though the terms symptomatic and asymptomatic have been in use mostly in the medical field. Today thanks to coronavirus even those of us who are non -medical can easily discern the difference.

\section{Lockdown}

The word lockdown is a compound word made up of two free lexical morphemes or a lexeme containing two or more potential stems. It is a prison protocol used to block people, information or cargo from leaving an area. When put under a full lockdown people are not allowed to move and may not enter or exit a building or rooms within the said building or area. In its formation, Miranda [37] asserts that lockdown is coined by a mere juxtaposition of the derivational bases i.e. lock and down, without any linking elements. Structurally, it is an example of a compound consisting of a simple stem. During the COVID-19 pandemic, the term lockdown underwent some form of semantic shift and has been used in relation to mass quarantines and not in the traditional sense of the word as explained above. The term lock down has therefore become a common vocabulary used in day-to-day conversations. For example, Kenya was placed under partial lockdown through a dusk to dawn curfew. Places that proved to be hotspots were put on a further partial lockdown within a lockdown through cessation of movement within those areas in order to break the chain of the spread of COVID-19.

\section{Contact tracing}

Contact tracing is another example of a compound word that is coined by a mere juxtaposition of the derivational bases without linking elements. The same is true of the following two terms associated with the three basic steps of contact tracing: Contact identification and Contact listing. The third step - Contact follow-up however is a different type of compound word that consists of a noun and the adjective. In its formation, the noun contact is formed without a linking element but the adjective follow-up has a linking element. The term contact follow-up is a compound word used in post COVID -19 vocabulary to refer to the act of identifying and following up people who have been in close contact with persons who are infected. Since the word "follow-up" modifies the noun "contact", it is hyphenated so as to avoid any misunderstanding that may arise between follow up and follow-up. In the case of COVID-19, the term contact tracing according to the WHO,[27] involves tracing people who have been in close liaison with persons infected with a virus and are at a higher risk of becoming infected themselves, and in the process are likely infect others. Keeping a close watch on such contacts after 
exposure will help the contacts to get care and treatment, and in the prevent further transmission of the virus. Contact tracing involves 3 basic steps mentioned above. When systematically applied, it can break the pattern of transmission of infectious diseases, making it an essential public health tool for controlling infectious disease outbreaks.

\section{Epidemic vs. Pandemic}

The terms Epidemic and pandemic have also acquired prominence in the post COVID-19 vocabulary. These terms fall under medical jargon. However, in post corona, they have become part and parcel of everyday vocabulary understood even by lay people. The two terms gained prominence on March 11, 2020, when the WHO declared the new coronavirus (COVID-19) a pandemic. From this pronouncement, the difference between the two terms started to be clear for most lay people. An epidemic disease affects many people at the same time by spreading from person to person in a locality where the disease is not permanently prevalent. A pandemic, on the other hand, is a global outbreak of a disease emanating from a new virus. As compared to an epidemic, a pandemic depends on geographic spread describes a disease that affects a whole country or the entire world. In other words, a pandemic disease is an epidemic that has spread over a large area, or it occurs throughout an entire country, continent, or the whole world. Old terms now more prominent. The two are examples of metalanguage or jargon which have been adopted during the pandemic to suit the purpose of the users.

\section{Incubation period}

The term incubation period came into the public eye for most people during the AIDS pandemic. Today however, due to COVID-19, the term is back into the common vocabulary and does not appear to be jargon anymore. In medicine, the term incubation refers to the time from the moment someone is exposed to an infectious agent until the time they exhibit symptoms of the disease. COVID-19 has an average incubation period of 5-6 days, but it can go up to 14 days. During e pre-symptomatic period, someone who is infected can be contagious. Therefore, it is possible that the disease is a pre-symptomatic case before the inception of symptoms or when one is asymptomatic. Incubation period is a compound word made up of two different lexemes with two different bases. As a medical jargon, in the COVID-19 vocabulary it changed its register by moving from the field of medical jargon to ordinary register.

\section{Ventilators vs. Respirator}

When the virus or an infection has caused the lungs to fail, ventilators are used assume the process of breathing which the body is unable to at that moment giving the patient time to fight off the infection and recover. Similarly, a ventilator therefore enables mechanical ventilation which moves air into and out of the lungs and in the process deliver breaths to a patient who is physically cannot breathe, or is breathing insufficiently. [28] A respirator by contrast is a masklike device, worn mostly by medical personnel over the mouth, or nose and mouth, to check the breathing in of noxious substances or the like. A respirator is used by health professionals to filter out virus particles as they breathe in so they don't get infected with COVID-19 in the process of assisting patients. In the COVID vocabulary, the terms ventilator and respirator have changed their register by moving from the field of medical jargon to ordinary register and they have been able to enter public discourse.

\section{Intubation}

Another term that has gained prominence and is related to ventilators is the term intubation. During the process of intubation, a pipe known as an endotracheal tube (ET) is inserted through the mouth and into the airway so that a patient can be placed on a ventilator to help them breath during anesthesia, sedation, or severe illness such as COVID-19. The ventilator then would push air into the lungs to deliver a breathable air to the patient. If we view jargon as unnecessarily complicated language used to impress, rather than to inform, ones audience, the term intubation would be seen as such since it is outside the realm of ordinary people however by changing its register and also moving from the field of medical jargon to ordinary register during the pandemic, it serves to demystify its meaning and usage.

\section{Screening}

Screening is the speculative identification of undetected disease in an otherwise healthy or asymptomatic population. Screening can be done through tests, examinations or other strategies that can be used swiftly and with ease on the target population. In this way, the word is part of medical jargon. However, COVID-19 has somehow managed to demystify its use as a process - one that begins with at the level of invitation to participation and ends with treating the appropriately identified individuals. Screening is a strategy used to look for as-yet-undetected conditions or risk factors. For COVID-19, when one is screened and found to be positive, those who are symptomatic are taken to hospital for treatment and quarantine centers for those who are asymptomatic. The WHO announcement on June 8, 2020 that asymptomatic spread of coronavirus is very rare influenced and changed rules that governed screening people for COVID-19. Government responses focused on 
detecting and isolating infected people with symptoms. The shift in stylistic usage of the word screening marks it as a neologisms.

\section{Quarantine vs. Isolation}

Another two terms that are now part and parcel of everyday vocabulary world over are quarantine and isolation. The term quarantine refers to a strict isolation regime forced on people to put to a stop the spread of disease. The practice of a quarantine specifically involves segregating people or groups of people who may have come into contact with a communicable disease but are asymptomatic, from others who have not been exposed so as to arrest the possibility of the spread of the communicable disease. In contrast, isolation is a noun which specifically refers the act of completely separating a person suffering from contagious or infectious disease from others. People may be quarantined when they are not currently sick, but have in one way or another have come into contact with a communicable or infectious disease. On the other hand, they may be placed in isolation if they currently have a communicable disease and can potentially infect others. This act thus separates them from people who are healthy helping to stop the spread of the disease. The term quarantine and isolation are examples of medical jargon that has been used over the years. However, due to the pandemic ravaging the world today as already existing words, they have gained more currency in their use due to the existing social situation.

\section{Voluntary quarantine and voluntary isolation}

Voluntary quarantine occurs when someone is not coerced into quarantine but does so on their own volition out of abundance of caution. It is also called self-quarantine. This a strategy that helps stop the disease from spreading. Voluntary isolation, on the other hand, sometimes also called self-isolation, happens when an individual separates him/herself from others if they suspect they are infected although it may not mean they are actually infected. These two terms are formed through the process of compounding. Since they consist of two units each - the term voluntary which is an adjective and the quarantine which is a noun. The term voluntary therefore acts as a noun modifier, thus voluntary quarantine is an example of a compound noun. The same is true of voluntary isolation which is also a compound noun consisting of the adjective voluntary and the noun isolation. They are examples of already existing words that have gained more currency in their usage due to the existing social situation - COVID-19.

\section{Plateau}

A plateau, also known as tableland, is a flat landform that rises sharply above the surrounding area on at least one side. Plateaus are part of the four major landforms, which also include: mountains, plains, and hills. Plateaus can also be found on every continent on earth. Plateaus occupy a third of the land on earth's surface. So what does the word plateau mean in the field of medicine in relation to COVID-19? Since the goal of health officials is to prevent a huge peak in COVID-19 cases in order to have a slower growth, we can use an analogy of a moderate plateau. In medical terms a plateau is seen as a period or state where there is little or no growth or where there is decline in a disease or a situation so as to stop it from progressing. Medically, it refers to the act of reaching and remaining at a stable level of achievement or leveling off. The meaning borrowed from the word plateau for COVID-19 is its flatness. In COVID-19 prevention and cure, the aim is to get to a point where the number of cases is on the decline. The period or state of little or no growth or decline is the plateau. The term Plateau, as used in the COVID-19 vocabulary, has undergone a sematic shift from its use as a geographic term denoting flatness of a landform to denote the flatness but to connote a point where there is no increase in the number of infected people.

\section{Flattening the curve}

This expression is related to the term plateau and it has also been constantly used during this COVID-19 period. If we view a curve as a noun that denotes a line that bends continuously with no straight parts, and flatten as a verb that means the process of making something flat or level, then we understand that this is verb compound. According to Specktor [29], "curve" refers to the number of people who are projected to contract COVID-19 over a period of time. In epidemiology flattening the curve refers to the slowing of a virus' spread so that fewer people may seek treatment at once. A flatter curve is a reflection of what happens when the spread of the virus is slowed down. In other wards even if the same number of people are taken ill, the infections happen over a longer period of time, giving hospitals time and space to treat everyone. Flattening the curve as a community isolation measure assists in keeping the daily number cases at a controllable level for medical providers to deal with the situation. Measures that can be put in place to achieve this include: the use of social distancing and stay-at-home orders, mandatory wearing of masks, regular hand washing using soap etc. all of which minimize and hold up the peak of active cases, thus allowing more time to build healthcare capacity that increases the possibility coping better with patient load. This is also an example of already existing phrase that has gained more currency in their usage during COVID-19.

\section{New normal}

The term new is an adjective that can mean something 
that is newly discovered or something brought to light for the first time and has not been in existence before. The word new can refer to something that have been already in existence but has been seen, experienced, or acquired recently or now for the first time. On the other hand, the word normal is also an adjective used to mean conforming to a standard, that is usual, typical, or expected. Thus, the expression new normal is made by bringing together the two lexemes to give us a new expression. It is a compound adjective. Before the advent of COVID-19, the world had expected standards it was conforming to. However, after corona all this changed and people had to adopt new ways of doing things different from what was considered normal then. The new normal entails the changes that have taken place since the advent of COVID-19 to our prior normal life. Our social cultural ways of doing things have been disrupted, be it at work, at home, and our social life have all been altered permanently. A "new normal" is about new ways of doing things and about how we live, work and interact with others. Since most viral diseases including COVID-19 have no cure to date, people have to learn to adapt their lifestyles to live with the virus. When a previously unfamiliar or a typical situation becomes standard, usual, or expected, then we talk of a new normal. A new normal result from something unusual like COVID-19. Its effects have been disruptive and people will have to learn to live with the virus and find new ways of adapting. The expression new normal is a compound adjective that explains life BC and life AC.

\section{Herd immunity}

Herd immunity is another example of a noun compound. It is derived from the word herd which can function as a noun or as a verb. The word immunity on the other hand, is also a noun that refers to the ability of an organism to resist a particular infection. Herd immunity is one of the terms that is currently in use in the COVID-19 vocabulary and can means group immunity or the ability to resist the spread of a contagious disease because a population has a sufficiently high number of people immune to the disease. This is a term in epidemiology which describes a situation in which a population has enough immunity to an infectious disease, to the extent of which the infection is unable to spread within the population. Herd immunity can be developed naturally or through vaccinations. According to van Schaik, "Herd immunity describes a situation where individuals who are at risk are protected from infectious diseases because they are surrounded by individuals who are immune, thus minimizing the spread of the virus. Some countries have been toying with the idea of taking this approach in the fight against COVID-19. However, many nations have resorted to the WHO protocols of combating the disease. [30] As a concept in epidemiology, it falls under medical jargon; however, under the COVID-vocabulary it is now used as an ordinary word.

\section{Frontline soldiers}

Frontline soldiers are a compound noun denoting the military line or part of an army that is closest to the enemy. Following the analogy of frontline soldiers, nurses and paramedics and essentially all health workers around the world are now frontline soldiers against COVID-19. Health care workers are facing a number of challenges such as out of the ordinary workload in inadequate health facilities, working in a stressful and frightening environment while risking their lives because the virus is little understood and also because they are under-protected and vulnerable to infection. Since they too have families, they are naturally scared that the virus might reach those they love most. Like many soldiers, who have seen first-hand the horrors of war health care, workers are also frontline soldiers in the war against COVID-19. They need everyone's support and protection from governments. The expression frontline soldiers associated with the military has undergone semantic shift in its usage under the COVID-19 vocabulary.

\section{Relaxing the restrictions}

Relaxing can mean reducing tension or anxiety while restrictions mean the limitation or control of someone or something, or the state of being restricted. Relaxing the restrictions is thus a compound noun. After months of drastic and restrictive measures put in place to slow the spread of COVID-19, many nations have taken to relaxing the restrictions. A restriction is an official rule that limits what you can do or that limits the amount or size of something. Many rules were put in place at the beginning of this pandemic - rules on quarantines, lockdowns, shelter in place, social distancing etc. However, today some of these rules are being relaxed in many countries have adopted cautious optimism, as they begin to carefully wind back some of the most stringent restrictions imposed during the pandemic. This is being done in a phased approach to avoid new waves of the corona virus outbreak.

\section{Devastation}

The COVID-19 pandemic has had disastrous effects. One of the terms used to describe this is the term devastation which has the denotation of great destruction or damage, economic, social etc. However, devastation accessioned by COVID-19 has connotations that go beyond a health crisis. Its effects have been devastating and have been felt at the social, economic and political levels. People all over the world are losing jobs and income on a daily basis, with no hope in sight and with no 
way of knowing when normality is likely to return. The ILO estimates that by the end of the second quarter of 2020 job loses would be in the range of between $5.9 \%$ and $11.9 \%$ or about 140 million to 340 million jobs could be lost. The pandemic continues to ravage companies by strangling their revenue streams putting some on their death beds. Kaberia, in an article in The Daily Nation June 23, 2020, indicated that more than 20 million Kenyans are expected to lose their jobs, businesses and sources of livelihoods as staff, students and pupils in schools, colleges and Universities adapt to new ways of learning. The April job forecast report for the US was everything but rosy. It indicated that the country lost 20.6 million jobs from mid-March, resulting in an unemployment rate of $14.7 \%$, a level not seen since the Great Depression in the 1930s. Allen [31] points out that Research and data clearly indicate that a huge portion of the job losses will be permanent. the effects of what she calls coronavirus recession-arguably a depression-will last much longer than expected, and that the unemployment numbers are higher than currently reported. This will definitely be part of the new normal.

\section{Syndromic surveillance}

The word syndromic is an adjective which means occurring as a syndrome or part of a syndrome. While the word surveillance is a noun that refers to a watch kept over a person, group, etc. The term syndromic surveillance therefore is an adjective compound that has gained prominence during the COVID-19 period. The term refers to ways of detecting individual and population health indicators that are discernible before confirming diagnoses. The objectives of syndromic surveillance are the identification of illness clusters early, before confirming diagnoses so as to make reports to public health agencies, in view of mobilizing a rapid response, in effect reducing morbidity and mortality. [32] Syndromic surveillance therefore is one of the strategies employed in the fight against COVID-19 by identifying illness clusters early confirming diagnosis and enabling mobilization of quick responses. [33]

\section{Home schooling}

The term home schooling is a noun compound made up of the noun home - the place of permanent residence, especially as a member of a family and schooling which means education obtained at school. This term is an oxymoron due to the inherent contradictions it exhibits. Schooling is done in school not at home according to the literal understanding of the term. However, home schooling is another "new" aspect of its meaning that has been highlighted due to COVID-19. The term itself may not be new but its implementation is new in some countries. If homeschooling is the education of children at home by their parents, then this will be largely a new concept in Kenya. Kenyan parents take their children to either private or public schools to be taught by qualified teachers. With COVID-19. the notion of home schooling has been touted a lot. While there maybe a few parents who actually home school their children, majority of parents in Kenya don't.

The examples above are words or phrases that have undergone semantic shifts or gained prominence. Language changes occasioned by the COVID-19 pandemic can be accounted for to some extent by the etymological theory which defines neologisms as words that exist in a language but have acquired a new meaning or undergone semantic shift. Most of these words and phrase are part of medical jargon; however, they have undergone change in their register by moving from the field of medical jargon to ordinary register during the pandemic and in a way, it serves to demystify their meaning and usage.

\section{Conclusion}

According to Nordquist [43], language change is an occurrence by which alterations are made in the attributes and the use of a language over time. All natural languages can change and these changes are normally reflected in areas of language use. Language changes can be manifested in its sound patterns, its lexis, in semantics, and in its syntax. Changes in language may be systematic or sporadic. During a time of social crises like COVID-19 pandemic, language of social crisis is used and there is normally an explosion of new words and phrases like those discussed above. The neologisms addressed above are useful since they function to help people communicate their fears about the biggest health crisis ever seen in generations. It collates people around a set of collective cultural reference points - it therefore acts as a kind of lexical "social glue". Since regular social contact is nonexistent due to the virus, shared communication becomes important part of assisting people feel the connection. The instant access to social media which is now part and parcel of our lives - has made it possible for people to share content with friends and family through our online connections. This means that there are now far more opportunities for individuals to piece together new terms and share them beyond their immediate local communities. Lawson [35]

From the above discussion, it is clear that the spread of coronavirus disease has changed the lives of billions of people worldwide. Likewise, it has ushered in a new set of lexicon that encompassing specialist terms from the fields of epidemiology and medicine to the general populace. New acronyms have been created, and words coined to express the societal importance of the imposed isolation and social distancing. The above discussion therefore 
indicates that language changes to accommodate new happenings in society. - Like the COVID-19 pandemic. The changes discussed above focus on the vocabulary level because grammatical and phonological structures are relatively stable but vocabularies can change very quickly both in words and in meanings. We have examined neologisms occasioned by COVID-19 under how existing words or expressions have acquired new meaning (semantic shift) or prominence, and completely new coinages through blending or acronymy.

"When there is significant social or civic change has happened during the time of the COVID-19 pandemic, linguistic creativity reflects the major preoccupations of the time and is able to show how people gather to talk about new challenges and contexts. As long as coronavirus is on rampage, understanding the language surrounding it will be ever more important.” Lawson [36]

\section{REFERENCES}

[1] Britannica Language - Neologisms Online available: https://www.britannica.com > topic > language > Neologisms

[2] Wikipedia. Online available: (https://en.wikipedia.org > wiki > Neologism).

[3] Britannica. Language - Linguistic change Online available: www.britannica.com > topic > Linguistic-change

[4] Neologism in the lexical system of modern English - GRIN. www.grin.com > document

[5] Noviarianti Oz. Background The study of language change: Language and changes. www.academia.edu > Language Change.

[6] Linguistics 001.Lecture 22.Language Change. Types of Language Change. Online available: www.ling.upenn.edu > courses > Fall_2003 > ling001

[7] Word formation. Online available: iugaza.edu.ps > files >

[8] Robert Bogdan and Steven J. Taylor. Introduction to Qualitative Research Methods. New York: WileyInterscience, 1975.

[9] Danko Šipka, Osnovi leksikologije i srodnih disciplina, Matica srpska, Novi Sad, Word formation of blends. docplayer.net > 195305955-Word-formation-of-blends. 200 6

[10] Irina Rets. Teaching Neologisms in English as a Foreign Language Classroom. www.researchgate.net > publication > 309343582_Teachi.

[11] Rets, I. Studying the new vocabulary of the Dutch language in the context of globalization. Philological sciences. Theoretical and practical questions, 6, 149-152, 2014.

[12] Nikolay Shamne \& Irina RetsIrina Rets. The Problem of Studying Neologisms and Their Influence on the Ecology of Language. 2015. DOI: 10.15688/jvolsu2.2015.1.8. www.res earchgate.net > publication > 281476409_The_Pr..
[13] M.A.K Halliday. Introduction to FunctionalGrammar.Hodd er Arnold. 2013

[14] Smarp. How does Information Overload affect your business and how to stop it? Online available: https://blog.smarp.co $\mathrm{m}$, how-does-information-overload-affect-your-busi... (2020)

[15] VSee. What is Telemedicine? All You Need To Know: Explained. On line available: https://vsee.com , what-is-telemedicine

[16] Nairobi new. (May 26th, 2020). Sick Kenyans now avoiding hospitals for fear of contracting... online available: https://nairobinews.nation.co.ke > life > sick-kenyans-now-a voiding-hospit...

[17] Dictionary.com. New Words We Created Because Of Coronavirus - Dictionary ... online available:https://www.d ictionary.com

new-words-we-created-because-of-coronavirus

[18] Dictionary.com. New Words We Created Because Of Coronavirus - Dictionary ... online available:https://www.d ictionary.com new-words-we-created-because-of-coronavirus

[19] Meredith Hart (2019) What Does WFH Mean? A Quick Guide - Owl Labs. Online available: https://www.owllabs.c om > blog > wfh-meaning

[20] Hijazi, M. F. l-Pixtisaraat l-hadiӨaa fi wassael al-ilam beinal-tarjama Al-Arabia wa al-iqtiradh al-majami [Modern abbreviations in the media between the Arabic translation and lexical borrowing]. Journal of the Arabic Language Academy, 92, 95-112. (2001).

[21] Yule, G. The Study of Language. Online available: www.studocu.com > inglese-i > riassunti > view 2018

[22] Walansky, Aly Virtual Happy Hours Are the New Way to Go Out: Here's how ... Online available:https://www.forbes .com > sites > alywalansky > 2020/03/26 > virtual-happ... (2020)

[23] Ehrman, J.P. Are You Experiencing Coronavirus Quarantine Fatigue... Health Essentials. Online available: https://health .clevelandclinic.org are-you-experiencing-coronavirus-quar... (2020)

[24] Kamaru Kairu in the Daily Nation of May, 4, 2020

[25] Rets, I. Studying the new vocabulary of the Dutch language in the context of globalization. Philological sciences. Theoretical and practical questions, 6, 149-152, 2014.

[26] WHO. Contact tracing - World Health Organization. Online available: https:// www.who.int > Newsroom > Q\&A Detail

[27] Ventilator - Wikipedia. Online available: en.wikipedia.org > wiki > Ventilator

[28] Specktor, B. Coronavirus: What is 'flattening the curve,' and will it work? Online available: www.livescience.com , coronavirus-flatten-the-curve

[29] Science Media Centre (202). Expert comments about herd immunity Online available: https://www.sciencemediacente r.org > expert-comments-about-herd-immu...

[30] Terina Allen (2020). Bitter Truths about Coronavirus Job Losses and the Economy. Online available: 
https://www.forbes.com > sites > terinaallen > 2020/05/10 > 3-bitter-truths-...

[31] K. D. Mandl. (2004). Implementing Syndromic Surveillance: A Practical Guide Informed by the Early Experience...Online available: https://www.ncbi.nlm.nih.go v > pmc > articles > PMC353021

[32] CDC. Morbidity and Mortality Weekly Report. Online available: https://www.cdc.gov > mmwr
[33] Richard Nordquist (2019), Language Change, Glossary of Grammatical and Rhetorical Terms. ThoughtCo. Online available: https://www.thoughtco.com > English > English Grammar

[34] Robert Lawson. The conversation. theconversation.com > coronavirus-has-led-to-an-explo. April 28 ${ }^{\text {th }}, 2020$

[35] Robert Lawson. The conversation. theconversation.com , coronavirus-has-led-to-an-explo. April 28th, 2020 